\title{
Estratégias de resistência: enfrentamento ou passividade frente aos problemas de gestão, revisão sistemática da literatura
}

Alessandra Paula Ferreira Moreira Neumann" ${ }^{1}$ Regina Helena Petroni Mennin²; Francisco Antonio de Castro Lacaz ${ }^{3}$.

\section{Resumo}

Foi realizada uma revisão sistemática da literatura para se analisar evidências científicas sobre formas de resistência dos trabalhadores à gestão do trabalho em saúde. Selecionouse 25 publicações nacionais e internacionais utilizando estudos qualitativos que foram avaliados através de Análise de Conteúdo, segundo núcleos temáticos de sentido e categorias, classificados em três dimensões: 1) Sofrimento; 2) Estratégias de resistências; 3) Proposições para melhorar gestão do trabalho. As proposições apontadas por trabalhadores e autores apresentam importante relação com a prática da Educação Permanente em Saúde e qualidade de vida $\mathrm{n}(\mathrm{d})$ o trabalho, permitindo levantar proposições e soluções para lidar com o sofrimento psíquico e físico no trabalho em saúde, visando melhorar os processos de trabalho.

Palavras-chave: Trabalhadores; Enfrentamento; Resistência; Sofrimento; Gestão.

\begin{abstract}
A systematic review of the literature was conducted to analyze scientific evidence relating to the ways in which workers cope with the management of health work. Twenty five national and international qualitative studies were evaluated using content analysis according to thematic units of meaning and categories, classified into three dimensions: Several units and categories identified in three dimensions: 1) suffering; 2) strategies of coping; 3) proposals to improve management. The propositions identified by workers and authors have an important relationship with the practice of Continuing Education in Health and quality of life $\mathrm{n}(\mathrm{d})$ work. Giving voice to workers allowed them to raise propositions and solutions to deal with the psychological and physical suffering in health at work and to improve work processes.
\end{abstract}

Keywords: Workers; Coping; Resistance; Suffering; Management.

1 Doutora em Saúde Coletiva. Aluna de Pós-doutorado do Programa de Pós-Graduação em Saúde Coletiva da Universidade Federal de São Paulo. Endereço: Rua Botucatu, 740, 4º andar Vila Clementino/São Paulo - Brasil CEP: 04023-062

2 Doutora em Saúde Pública. Docente do Departamento de Medicina Preventiva da Escola Paulista de Medicina da Unifesp. Coorientadora da dissertação. São Paulo, Brasil.

3 Doutor em Saúde Coletiva. Docente do Departamento de Medicina Preventiva da Escola Paulista de Medicina da Unifesp. Orientador da dissertação. São Paulo, Brasil. 


\section{Introdução}

Sabe-se que ao longo da história há citações de resistência do movimento negro; nos discursos e ações dos trabalhadores sem-teto; nos movimentos feministas, indígenas, e dos trabalhadores do campo, bem como nos movimentos de estudantes e trabalhadores urbanos (NEUMANN, 2014, p. 8).

Quando se pensa na palavra "resistência" aparentemente ela não parece trazer dúvidas sobre seu significado, entretanto, quando se faz uma pesquisa sobre sua origem e significado nos dicionários, encontra-se as seguintes definições, "Ato ou feito de resistir e segundo como uma força que se opõe a outra" (FERREIRA, 1999, p.1752) e o Grande dicionário Larousse (1999, p.786) além dessas definições inclui 3. Capacidade de resistir às fadigas físicas ou aos infortúnios morais. 4. Força que anula os efeitos de uma ação destruidora. 5. Defesa contra um ataque. 6. Oposição, reação, recusa de submissão à vontade de outrem [...].

Para Foucault (1986) o conceito de resistência está ligado ao de subjetivação, na medida em que resistir e subjetivar-se remete a um modo de produção do sujeito cujas relações de força agem tensionando, e considera que não deixar-se assujeitar é resistir, é abrir-se a outros modos de ser sujeito, ainda que desconhecidos.

Considerando que a resistência está diretamente ligada à submissão no trabalho, afirmam dialeticamente Mendes e Dias (1991, p. 347) que "[...] a Saúde do Trabalhador considera o trabalho, enquanto organizador da vida social, como o espaço de dominação e submissão do trabalhador pelo capital, mas, igualmente, de resistência, de constituição e do fazer histórico".

As dificuldades no trabalho são motivos de preocupação para profissionais, das mais variadas áreas de atuação. Assim convém perguntar, "[...] até que ponto os trabalhadores podem reclamar, exigir, defender-se, resistir? Têm eles (as), teoricamente esse direito?’ (VIANA, 1996, p.29).

Assim, atualmente, o maior desafio não é somente o reconhecimento do direito à saúde dos trabalhadores, já que as normas jurídicas a respeito são numerosas e suficientemente claras para proclamá-lo. "A luta que deverá ser travada é para que esse direito já consagrado objetivamente venha a incorporar-se na realidade dos ambientes e 
processos de trabalho, no dia a dia do trabalhador.” (OLIVEIRA, 2002, p.78), mas também como os trabalhadores resistem aos problemas de gestão.

\section{Abordagens das relações trabalho e saúde mental}

Uma abordagem bem conhecida, a Psicodinâmica do Trabalho tem como campo de estudo o homem e sua interação com o ambiente de trabalho, com a organização do trabalho e as situações geradas nesse âmbito. (BRUCH, MONTEIRO, 2011). Essa abordagem surgiu na década de 1950 sendo o psiquiatra Le Guillant (1900-1968) um de seus fundadores, naquela as pesquisas voltavam-se para os quadros neuróticos ou psicóticos associados ou não ao suicídio (CODO, 2002).

As pesquisas avançam e Codo pesquisando sobre doenças mentais e trabalho, conclui que "o sofrimento psíquico e a doença mental ocorrem quando e apenas quando, afeta esferas da nossa vida que são significativas, geradoras e transformadoras de significado" (CODO, 2002, p.174).

Assim o sofrimento dos trabalhadores ganha destaque e alguns autores mencionam a importância de se dar visibilidade “[...] ao processo de transformação do sofrimento em adoecimento" (BRANT e MINAYO_GOMES, 2009, p.214), especialmente quando coexistem situações políticas (dominação e resistência), de gozo (mesclagem de prazer e dor) e econômicas (prescrição e consumo abusivos de medicalização).

O conceito de organização do trabalho na interpretação de Dejours (1987) está relacionado à tarefa desenvolvida, à divisão do trabalho, ao sistema hierárquico, às relações de poder, responsabilidade e modalidade de comando e pode se tornar uma fonte de sofrimento psíquico no trabalho. O sofrimento mental resultante da insatisfação do trabalhador com seu ambiente de trabalho pode desencadear o processo de adoecimento (DEJOURS et al., 1994; SELIGMAN-SILVA, 1994; LAURELL e NORIEGA, 1989). Enquanto que condição de trabalho é considerada como sendo as circunstâncias ambientais de caráter físico, químico e biológico; envolvendo também a segurança, a ergonomia e condições de higiene; bem como as características do posto do trabalho, podendo influenciar também a saúde dos trabalhadores (LAURELL e NORIEGA, 1989; DEJOURS et al., 1994). 
Dessa forma, trabalhadores podem adoecer ou morrer por eventos relacionados ao trabalho, como consequência das atividades que exercem ou exerceram, ou pelas condições adversas em que seu trabalho é ou foi realizado (MENDES e DIAS, 1991).

Assim, busca-se responder no que consistem as formas de resistência dos trabalhadores à gestão do trabalho em saúde para a proteção ao sofrimento físico e psíquico encontradas na literatura.

\section{Método}

Trata-se de pesquisa sobre publicações nacionais e internacionais como parte da dissertação de mestrado em Saúde Coletiva intitulada "As estratégias de resistência ao sofrimento psíquico e físico relacionadas à gestão do trabalho em saúde: um estudo de revisão sistemática da literatura", a respeito das estratégias de resistência ao sofrimento psíquico e físico no âmbito da realidade dos trabalhadores da área da saúde.

Foi realizado um estudo de revisão sistemática da literatura, que segundo Santos (2006) pode reconhecer e dar crédito à criação intelectual de outros autores. As revisões sistemáticas resgatam pesquisas originais, de artigos completos e publicados, que foram analisados e avaliados quanto à qualidade, através de um levantamento nas bases de dados LILACS, MEDLINE e SCIELO, em português, inglês e espanhol, na área da saúde através da Biblioteca Virtual Bireme e portal Capes.

Os critérios de inclusão dos artigos foram: periódicos científicos indexados; idioma de publicação, ou seja, em língua Portuguesa, Espanhola e Inglesa; ano de publicação compreendido entre abril de 2009 a abril de 2014; artigos que tinham recorte qualitativo e que apresentassem a fala transcrita dos sujeitos participantes do estudo. Os critérios de exclusão foram: artigos repetidos nas bases de dados; títulos e resumos que não tinham relação com a gestão do trabalho em saúde; artigos que apresentassem apenas dados quantitativos sem a fala dos trabalhadores.

Para realizar o tratamento analítico, adotou-se três grandes etapas conforme proposto Análise de Conteúdo (AC) (BARDIN, 2004): pré-análise, exploração do material, tratamento dos resultados e interpretação.

O conteúdo dos artigos encontrados foi interpretado, segundo AC que considera esta um conjunto de técnicas de análise das comunicações e que visa obter por 
procedimentos sistemáticos e objetivos a descrição do conteúdo das mensagens. Para o 'reagrupamento' dos achados da análise do material empírico foram criados 'núcleos de sentido, categorias e subcategorias' (BARDIN, 2004).

O estudo foi submetido ao Comitê de Ética em Pesquisa da Universidade Federal de São Paulo (CEP/UNIFESP/Hospital São Paulo), com protocolo de pesquisa aprovado pelo Parecer no 186.723 de 11/01/2013.

\section{Resultados e discussão}

O total 1010 artigos foi o número inicial, muitos desses tinham resumos incompletos, o que dificultou identificar o objeto de estudo, ou falavam apenas de resistência física. Diante disso, 335 artigos foram selecionados para análise dos resumos, visando uma análise preliminar para avaliar a pertinência em relação ao tema de estudo. Ao final desta abordagem metodológica foram selecionadas e analisadas 25 publicações.

Após a coleta de dados, foram construídos quadros e tabelas, utilizando os descritores e termos adotados, considerando as buscas efetuadas nas bases SCIELO, LILACS e MEDLINE. Segundo já referido, analisou-se 25 publicações em português, inglês e espanhol, conforme quadro 1.

Quadro 1 - Com artigos escritos em português 1-15, espanhol 16-20, inglês 21-25, selecionados para análise, conforme levantamento nas bases de dados Scielo, Lilacs e Medline, período de abril de 2009 a abril de 2014. 


\begin{tabular}{|c|c|c|c|c|c|c|}
\hline $\mathbf{N}$ & ANO & AUTORES & TÍTULO & DESCRIÇÃO DO ESTUDO & PERIÓDICO & BASE \\
\hline 1 & 2013 & $\begin{array}{l}\text { Janine K. } \\
\text { Monteiro; Artur } \\
\text { L.L.Oliveira; } \\
\text { Camila S. } \\
\text { Ribeiro; } \\
\text { Gabrielle H. } \\
\text { Grisa; Nivia } \\
\text { Agostini }\end{array}$ & $\begin{array}{l}\text { Adoecimento } \\
\text { psíquico de } \\
\text { trabalhadores de } \\
\text { unidades de } \\
\text { terapia intensiva. }\end{array}$ & $\begin{array}{l}\text { Realizaram entrevistas com } 8 \text { profissionais da área da } \\
\text { enfermagem, que apresentavam adoecimento mental } \\
\text { (depressão e/ou burnout) de dois hospitais privados na } \\
\text { região metropolitana de Porto Alegre/RS. }\end{array}$ & $\begin{array}{c}\text { Psicologia: } \\
\text { Ciência e } \\
\text { Profissão v.33 } \\
\text { n.2 } \\
\text { pp.366-379 }\end{array}$ & $\begin{array}{c}\text { SCIEL } \\
\mathrm{O}\end{array}$ \\
\hline 2 & 2012 & $\begin{array}{l}\text { Alcindo J. Rosa; } \\
\text { Ana L. Bonfanti; } \\
\text { Cintia S. } \\
\text { Carvalho. }\end{array}$ & $\begin{array}{l}\text { O sofrimento } \\
\text { psíquico de ACS e } \\
\text { suas relações com } \\
\text { o trabalho. }\end{array}$ & $\begin{array}{l}\text { Intervenção em unidades de saúde ESF em } \\
\text { Rondonópolis (MT) com } 6 \text { ACM através de entrevistas e } \\
\text { acompanhamento como observador em cinco visitas } \\
\text { domiciliares. }\end{array}$ & $\begin{array}{l}\text { Saúde e } \\
\text { Sociedade } \\
\text { vol. } 21 \mathrm{n} .1 \\
\text { pp. } 141-152\end{array}$ & $\begin{array}{c}\text { SCIEL } \\
\mathrm{O}\end{array}$ \\
\hline 3 & 2012 & $\begin{array}{l}\text { Vladimir } \\
\text { Athayde; Élida } \\
\text { Azevedo } \\
\text { Hennington; }\end{array}$ & $\begin{array}{l}\text { A saúde mental } \\
\text { dos profissionais } \\
\text { de um Centro de } \\
\text { Atenção } \\
\text { Psicossocial. }\end{array}$ & $\begin{array}{l}\text { Foi feita uma pesquisa com trabalhadores de um CAPS } \\
\text { no estado do Rio de Janeiro com } 13 \text { profissionais de } \\
\text { saúde mental (psicólogo, enfermeiro, terapeuta } \\
\text { ocupacional, médico, nutricionista, assistente social e } \\
\text { uma "danço- terapeuta") através de observação } \\
\text { participante, entrevistas individuais e análise } \\
\text { documental. }\end{array}$ & $\begin{array}{c}\text { Physis vol.22 } \\
\text { no.3 } \\
\text { pp.983-1001 }\end{array}$ & $\begin{array}{c}\text { SCIEL } \\
\mathrm{O}\end{array}$ \\
\hline 4 & 2012 & $\begin{array}{l}\text { Claudia N. } \\
\text { Magnus; Álvaro } \\
\text { C. Merlo }\end{array}$ & $\begin{array}{l}\text { A construção de } \\
\text { saúde, entre o } \\
\text { servir e a servidão: } \\
\text { das relações entre } \\
\text { servidores de um } \\
\text { hospital } \\
\text { psiquiátrico } \\
\text { público. }\end{array}$ & $\begin{array}{l}\text { Pesquisa feita com servidores públicos estaduais, } \\
\text { enfermeiro, auxiliar e técnico e enfermagem, } \\
\text { fisioterapeuta, psicólogo, assistente social e terapeuta } \\
\text { ocupacional, do Hospital Psiquiátrico São Pedro (HPSP) } \\
\text { no Rio Grande do Sul, por meio de entrevistas. }\end{array}$ & $\begin{array}{l}\text { Cad. Psicol.. } \\
\text { soc. Trab. } \\
\text { vol.15, n.2 SP } \\
\text { p.175-188 }\end{array}$ & LILACS \\
\hline 5 & 2011 & $\begin{array}{l}\text { Sandra } \\
\text { F.R.Ribeiro; } \\
\text { Sueli T. F. } \\
\text { Martins. }\end{array}$ & $\begin{array}{l}\text { Sofrimento } \\
\text { psíquico do } \\
\text { trabalhador da } \\
\text { saúde da família } \\
\text { na organização do } \\
\text { trabalho. }\end{array}$ & $\begin{array}{l}\text { Realizaram o estudo em uma Unidade Saúde da Família } \\
\text { (USF) de um município do Interior de São Paulo, com } \\
\text { quinze trabalhadores: } 5 \text { ACS, } 3 \text { auxiliares de } \\
\text { enfermagem, } 1 \text { enfermeira, } 2 \text { residentes (um de } \\
\text { enfermagem e um de medicina), } 1 \text { médica, } 1 \text { auxiliar } \\
\text { administrativo e } 1 \text { auxiliar de serviços gerais. Através } \\
\text { entrevistas e a observação participante. }\end{array}$ & $\begin{array}{l}\text { Psicologia em } \\
\text { Estudo vol. } 16 \\
\text { n.2 } \\
\text { p.241-250 }\end{array}$ & $\begin{array}{c}\text { SCIEL } \\
\mathrm{O}\end{array}$ \\
\hline 6 & 2011 & $\begin{array}{l}\text { Davi Baasch; } \\
\text { Aline S. Laner }\end{array}$ & $\begin{array}{l}\text { Os significados do } \\
\text { trabalho em } \\
\text { unidades de } \\
\text { terapia intensiva } \\
\text { de dois hospitais } \\
\text { brasileiros. }\end{array}$ & $\begin{array}{l}\text { Pesquisaram com oitenta trabalhadores, } 40 \text { no hospital } \\
\text { privado e } 40 \text { no hospital público, sendo, } 14 \text { médicos, } 17 \\
\text { enfermeiros, } 34 \text { técnicos de enfermagem, } 3 \text { técnicos } \\
\text { administrativos e } 12 \text { auxiliares de enfermagem, por meio } \\
\text { de aplicação de questionário e entrevistas } \\
\text { semiestruturadas. }\end{array}$ & $\begin{array}{l}\text { Ciênc. saúde } \\
\text { coletiva vol.16 } \\
\text { supl.1 } \\
\text { pp. } \\
\text { 1097-1105 }\end{array}$ & $\begin{array}{c}\text { SCIEL } \\
\mathrm{O}\end{array}$ \\
\hline 7 & 2011 & $\begin{array}{l}\text { Cássia B. } \\
\text { Batista; Augusto } \\
\text { S. Campos; } \\
\text { Juliana C. } \\
\text { Reis;Virgínia T. } \\
\text { Schall; }\end{array}$ & $\begin{array}{l}\text { Violência no } \\
\text { trabalho em saúde: } \\
\text { análise em } \\
\text { unidades básicas } \\
\text { de saúde de Belo } \\
\text { Horizonte, Minas } \\
\text { Gerais. }\end{array}$ & $\begin{array}{l}\text { Estudo com } 75 \text { trabalhadores de um distrito de saúde de } \\
\text { Belo Horizonte, através de grupos focais e entrevistas, } \\
11 \text { agentes comunitários de saúde; sete enfermeiros; } \\
\text { quatro médicos; três gerentes de UBSs; cinco gerentes } \\
\text { distritais; quatro profissionais do núcleo psicossocial } \\
\text { (assistente social, psicólogo e psiquiatra); seis } \\
\text { profissionais da equipe de saúde bucal (dentista e } \\
\text { técnico de higiene dental); sete auxiliares e técnicos de } \\
\text { enfermagem; oito auxiliares administrativos; seis } \\
\text { porteiros; oito auxiliares de serviços gerais; e seis } \\
\text { usuários. }\end{array}$ & $\begin{array}{c}\text { Trab. educ. } \\
\text { saúde } \\
\text { (Online) vol.9 } \\
\text { no.2 } \\
\text { pp.295-317 }\end{array}$ & $\begin{array}{c}\text { SCIEL } \\
\mathrm{O}\end{array}$ \\
\hline 8 & 2011 & $\begin{array}{l}\text { Katia } \\
\text { V.O.Feliciano; } \\
\text { Maria H. } \\
\text { Kovacs; Silvia } \\
\text { W. Sarinho }\end{array}$ & $\begin{array}{l}\text { Burnout entre } \\
\text { médicos da Saúde } \\
\text { da Família: os } \\
\text { desafios da } \\
\text { transformação do } \\
\text { trabalho }\end{array}$ & $\begin{array}{l}\text { Pesquisa qualitativa desenvolvida entre agosto de } 2005 \\
\text { e novembro de 2006, baseada em depoimentos com } 24 \\
\text { médicos da Estratégia Saúde da Família em diversos } \\
\text { distritos de Recife }\end{array}$ & $\begin{array}{c}\text { Ciência \& } \\
\text { Saúde } \\
\text { Coletiva v.16 } \\
\text { n.8 } \\
\text { pp.3373-3382 }\end{array}$ & $\begin{array}{l}\text { MEDLI } \\
\text { NE }\end{array}$ \\
\hline 9 & 2010 & $\begin{array}{l}\text { lara Ap.O. } \\
\text { Secco; Maria } \\
\text { L.C.C.Robazzi; } \\
\text { Francisco } \\
\text { E.A.Souza; } \\
\text { Denise S. } \\
\text { Shimizu. }\end{array}$ & $\begin{array}{l}\text { Cargas psíquicas } \\
\text { de trabalho e } \\
\text { desgaste dos } \\
\text { trabalhadores de } \\
\text { enfermagem de } \\
\text { hospital de ensino } \\
\text { do Paraná. }\end{array}$ & $\begin{array}{l}\text { Realizaram um estudo com } 7 \text { enfermeiras, detentoras de } \\
\text { cargo de chefia: a diretora de enfermagem, as } \\
\text { enfermeiras-chefe das } 5 \text { divisões/setores de } \\
\text { enfermagem do hospital que apresentaram maiores } \\
\text { indicadores de risco de ATTs e a enfermeira da } \\
\text { comissão de controle de infecção hospitalar, por meio } \\
\text { de entrevistas semiestruturadas. }\end{array}$ & $\begin{array}{l}\text { SMAD.Revista } \\
\text { eletrônica } \\
\text { saúde mental } \\
\text { álcool e } \\
\text { drogas v6.n1 } \\
\text { pp.1-17 }\end{array}$ & LILACS \\
\hline 10 & 2010 & $\begin{array}{l}\text { Cássia R.G. } \\
\text { Medeiros; Álvaro } \\
\text { G.W. Junqueira; } \\
\text { G. Schwingel; } \\
\text { loná Carreno; } \\
\text { Lucia A.P. } \\
\text { Jungles;Olinda } \\
\text { M.F.L.Saldanha }\end{array}$ & $\begin{array}{l}\text { A rotatividade de } \\
\text { enfermeiros e } \\
\text { médicos: um } \\
\text { impasse na } \\
\text { implementação da } \\
\text { Estratégia de } \\
\text { Saúde da Família. }\end{array}$ & $\begin{array}{l}\text { Realizaram um estudo quanti-qualitativo com } 7 \text { médicos } \\
\text { e } 7 \text { enfermeiros da equipe ESF no vale do Taquari (RS). } \\
\text { A primeira fase foi quantitativa, e na segunda fase foi } \\
\text { qualitativa, por meio de entrevistas semiestruturadas. }\end{array}$ & $\begin{array}{l}\text { Ciência \& } \\
\text { Saúde } \\
\text { Coletiva v.15 } \\
\text { sp.1 } \\
\text { pp.1521-31 }\end{array}$ & $\begin{array}{c}\text { SCIEL } \\
0\end{array}$ \\
\hline
\end{tabular}




\begin{tabular}{|c|c|c|c|c|c|c|}
\hline 11 & 2010 & $\begin{array}{l}\text { Eliana P. } \\
\text { Azambuja; } \\
\text { Denise } \\
\text { E.P.Pires; Marta } \\
\text { R.C.Vaz Maria } \\
\text { H. Marziele }\end{array}$ & $\begin{array}{l}\text { É possível produzir } \\
\text { saúde no trabalho } \\
\text { de enfermagem? }\end{array}$ & $\begin{array}{l}\text { Realizaram uma pesquisa qualitativa em Unidades de } \\
\text { Terapia Intensiva de dois hospitais situados na região } \\
\text { Sul do Brasil, utilizando-se observação e entrevistas } \\
\text { semi-estruturadas com a equipe de enfermagem. }\end{array}$ & $\begin{array}{l}\text { Texto \& } \\
\text { Contexto - } \\
\text { Enfermagem } \\
\text { v. } 19 \text { n.4 } \\
\text { pp. } 658-66\end{array}$ & $\begin{array}{l}\text { SCIEL } \\
\text { O }\end{array}$ \\
\hline 12 & 2010 & $\begin{array}{l}\text { Rodolfo A. G. } \\
\text { Vilela; } \\
\text { Reginalice C. } \\
\text { Silva; José M. J. } \\
\text { filho. }\end{array}$ & $\begin{array}{l}\text { Poder de agir e } \\
\text { sofrimento: estudo } \\
\text { de caso sobre } \\
\text { Agentes } \\
\text { Comunitários de } \\
\text { Saúde. }\end{array}$ & $\begin{array}{l}\text { A equipe do Cerest de Piracicaba realizou uma análise } \\
\text { ergonômica do trabalho, entrevistando } 5 \text { ACS em uma } \\
\text { unidade de saúde de família.. }\end{array}$ & $\begin{array}{l}\text { Revista } \\
\text { Brasileira de } \\
\text { Saúde } \\
\text { Ocupacional } \\
\text { v.35 n.122 pp. } \\
289-302\end{array}$ & $\begin{array}{l}\text { SCIEL } \\
\text { O }\end{array}$ \\
\hline 13 & 2009 & $\begin{array}{l}\text { Luiz C. Brant; } \\
\text { Carlos Minayo- } \\
\text { Gomez. }\end{array}$ & $\begin{array}{l}\text { Manifestação do } \\
\text { sofrimento e } \\
\text { resistência ao } \\
\text { adoecimento na } \\
\text { gestão do trabalho. }\end{array}$ & $\begin{array}{l}\text { Empreenderam uma investigação numa empresa } \\
\text { pública, de grande porte, do setor de serviços, numa } \\
\text { metrópole da região Sudeste do Brasil, entrevistando } \\
\text { vinte e um trabalhadores, sendo } 13 \text { gestores e } 08 \\
\text { profissionais da saúde. }\end{array}$ & $\begin{array}{l}\text { Saúde e } \\
\text { Sociedade } \\
\text { vol.18 no.2 } \\
\text { pp. } 237-247\end{array}$ & $\begin{array}{c}\text { SCIEL } \\
\text { O }\end{array}$ \\
\hline 14 & 2009 & $\begin{array}{l}\text { Tatiana A. } \\
\text { Tuacek; Selma } \\
\text { Tuacek; Maria I. } \\
\text { G. Ghirardi; } \\
\text { Eliane D. Castro; }\end{array}$ & $\begin{array}{l}\text { Repercussões da } \\
\text { violência na saúde } \\
\text { mental de } \\
\text { trabalhadores do } \\
\text { PSF. }\end{array}$ & $\begin{array}{l}\text { Realizaram uma pesquisa nas cidades de São Paulo, } \\
\text { Ribeirão Preto e Embu, com profissionais do PSF: } \\
\text { médicos, enfermeiros, auxiliares de enfermagem e } \\
\text { agentes comunitários de saúde, por meio de grupos de } \\
\text { reflexão. }\end{array}$ & $\begin{array}{c}\text { Rev. Saúde } \\
\text { Pública vol.43 } \\
\text { no. } 4 \\
\text { pp. } 682-8\end{array}$ & $\begin{array}{l}\text { MEDLI } \\
\text { NE }\end{array}$ \\
\hline 15 & 2009 & $\begin{array}{l}\text { Mey F.P.Wai; } \\
\text { Ana Maria P. } \\
\text { Carvalho }\end{array}$ & $\begin{array}{l}\text { O trabalho do } \\
\text { agente comunitário } \\
\text { de saúde: fatores } \\
\text { de sobrecarga e } \\
\text { estratégias de } \\
\text { enfrentamento. }\end{array}$ & $\begin{array}{l}\text { Realizaram entrevistas semi estruturadas com } 17 \text { ACS } \\
\text { da ESF no município de São José do Rio Preto-SP em } \\
2005 \text {, utilizando abordagem qualitativa exploratória, com } \\
\text { dois temas centrais: sobrecarga e estratégias de } \\
\text { enfrentamento. }\end{array}$ & $\begin{array}{l}\text { Revista de } \\
\text { enfermagem } \\
\text { UERJ } 17(4) \\
\text { pp. } 563-568\end{array}$ & LILACS \\
\hline 16 & 2013 & $\begin{array}{l}\text { Rosane T. } \\
\text { Fontana; Daiane } \\
\text { H. Nunes. }\end{array}$ & $\begin{array}{l}\text { Riesgos laborales } \\
\text { en la concepción } \\
\text { de los trabajadores } \\
\text { de uma lavandería } \\
\text { hospitalaria. }\end{array}$ & $\begin{array}{l}\text { Estudo realizado em uma lavanderia de um Hospital } \\
\text { Universitário de Maringá (PR) com } 10 \text { trabalhadores, por } \\
\text { meio de entrevistas. }\end{array}$ & $\begin{array}{l}\text { Enferm. Glob. } \\
\text { Vol.12 no29 } \\
\text { pp.170-182 }\end{array}$ & $\begin{array}{l}\text { SCIEL } \\
\mathrm{O}\end{array}$ \\
\hline 17 & 2012 & $\begin{array}{l}\text { Dois Castellón; } \\
\text { Angelina María; }\end{array}$ & $\begin{array}{l}\text { Hostigamiento } \\
\text { laboral: amenaza } \\
\text { permanente para } \\
\quad \text { enfermería }\end{array}$ & $\begin{array}{l}\text { Pesquisas qualitativa descritiva com } 13 \text { enfermeiros e } \\
\text { enfermeiras obstetras chilenos, por meio de entrevistas. }\end{array}$ & $\begin{array}{l}\text { Enferm. Glob. } \\
\text { Vol.11 no } 4 \\
\text { pp.105-136 }\end{array}$ & $\begin{array}{l}\text { SCIEL } \\
\text { O }\end{array}$ \\
\hline 18 & 2012 & $\begin{array}{l}\text { César B. } \\
\text { Abadía; María } \\
\text { A.. Pinilla., } \\
\text { Katerine Ariza } \\
\text { R.y Héctor C. } \\
\text { Ruíz S. }\end{array}$ & $\begin{array}{l}\text { Neoliberalismo em } \\
\text { salud: La tortura } \\
\text { de trabajadoras y } \\
\text { trabajadores del } \\
\text { Instituto Materno } \\
\text { Infantil de Bogotá. }\end{array}$ & $\begin{array}{l}\text { Realizaram entrevistas semi-estruturadas com } 5 \\
\text { mulheres que trabalhavam no Instituto Materno Infantil } \\
\text { (IMI), em Bogotá - Colombia, com } 1 \text { auxiliar de } \\
\text { enfermagem, } 1 \text { técnica de radiologia, } 1 \text { secretária, } 1 \\
\text { terapeuta ocupacional e } 1 \text { enfermeira chefe, propõem } \\
\text { analisar as conexões entre os diferentes tipos de } \\
\text { violência no neoliberalismo. }\end{array}$ & $\begin{array}{l}\text { Rev. Salud } \\
\text { pública v.14 } \\
\text { sppl.1 pp.18- } \\
31\end{array}$ & LILACS \\
\hline 19 & 2012 & $\begin{array}{l}\text { Laura R. Serna, } \\
\text { Diana C. G. } \\
\text { Ospina; Lina } \\
\text { M.R. Molina }\end{array}$ & $\begin{array}{l}\text { Posición afectiva } \\
\text { que asume el } \\
\text { personal de la } \\
\text { salud de las } \\
\text { Unidades de } \\
\text { Cuidados } \\
\text { Intensivos } \\
\text { pediátricos de la } \\
\text { ciudad de Medelín } \\
\text { en el primer } \\
\text { semestre de } 2010 .\end{array}$ & $\begin{array}{l}\text { Estudo qualitativo na cidade de Medelín com } 16 \\
\text { trabalhadores, médicos, profissionais de enfermaria, } \\
\text { auxiliares de enfermagem e terapeutas respiratórios, por } \\
\text { meio de entrevistas semiestruturadas. }\end{array}$ & $\begin{array}{l}\text { Medicina } \\
\text { U.P.B. v. } 31 \mathrm{n}^{\circ} \\
2 \\
\text { pp. } 151-159\end{array}$ & LILACS \\
\hline 20 & 2009 & $\begin{array}{l}\text { Paula R. A. } \\
\text { Díaz; } \\
\text { Ana M. A. } \\
\text { Muñoz; } \\
\text { Marcela L. L. } \\
\text { García; }\end{array}$ & $\begin{array}{l}\text { Protectores de } \\
\text { estrés laboral: } \\
\text { percepción del } \\
\text { personal de } \\
\text { enfermería y } \\
\text { médicos, temuco, } \\
\quad \text { chile }\end{array}$ & $\begin{array}{l}\text { Pesquisa com } 8 \text { trabalhadores, gestores de instituições } \\
\text { de saúde, auxiliares de enfermagem, enfermeiros / as e } \\
\text { médicos que trabalham em unidades hospitalares crítico } \\
\text { e crítico público não e privado média e alta } \\
\text { complexidade, de uma unidade de UTI na região de } \\
\text { Araucania no Chile, por meio de entrevistas. }\end{array}$ & $\begin{array}{l}\text { Enferm. Glob. } \\
\text { Vol.12 n-29 } \\
\text { pp. } 170-182\end{array}$ & $\begin{array}{c}\text { SCIEL } \\
\mathrm{O}\end{array}$ \\
\hline
\end{tabular}




\begin{tabular}{|c|c|c|c|c|c|}
\hline 21 & 2013 & $\begin{array}{l}\text { Rosane } \\
\text { T.Fontana; Liana } \\
\text { Lautert }\end{array}$ & $\begin{array}{l}\text { The situation of } \\
\text { nursing work and } \\
\text { occupational risks } \\
\text { from an ergological } \\
\text { perspective. }\end{array}$ & $\begin{array}{l}\text { Estudo realizado com } 25 \text { trabalhadores da enfermagem } \\
\text { em uma unidade básica de saúde em Rio Grande do Sul, } \\
\text { por meio de entrevistas e observação participante. }\end{array}$ & $\begin{array}{l}\text { Rev. Latino- } \\
\text { Americana } \\
\text { Enfermagem } \\
\text { v. } 21 \text { n.6 } \\
\text { pp. } 1306-1313\end{array}$ \\
\hline 22 & 2013 & $\begin{array}{l}\text { Meral Turk; Asli } \\
\text { Davas; Feride A. } \\
\text { Tanik; Anthony } \\
\text { J. Montgomery }\end{array}$ & $\begin{array}{l}\text { Organizational } \\
\text { stressors, work- } \\
\text { family interface } \\
\text { and the role of } \\
\text { gender in the } \\
\text { hospital: } \\
\text { Experiences from } \\
\text { Turkey. }\end{array}$ & $\begin{array}{l}\text { Estudo realizado com } 23 \text { profissionais de saúde, sendo } \\
02 \text { grupos com } 12 \text { enfermeiros e outro com } 09 \text { médicos. } \\
\mathrm{Na} \text { cidade de Esmirna na Turquia, por meio de } \\
\text { entrevistas e grupos focais. }\end{array}$ & $\begin{array}{l}\text { British journal } \\
\text { of Health } \\
\text { Psychology } \\
\text { v. } 19, \text { n. } 2 \\
\text { pp. } 442-458\end{array}$ \\
\hline 23 & 2012 & $\begin{array}{l}\text { Meredith Mealer; } \\
\text { Jacqueline } \\
\text { Jones; Marc } \\
\text { Moss }\end{array}$ & $\begin{array}{l}\text { A qualitative study } \\
\text { of resilience and } \\
\text { posttraumatic } \\
\text { stress disorder in } \\
\text { United States ICU } \\
\text { nurses. }\end{array}$ & $\begin{array}{l}\text { Entrevistaram } 27 \text { enfermeiros por telefone, em busca de } \\
\text { identificar a resiliência e a resistência como } \\
\text { característica que permitem aos enfermeiros a lidarem } \\
\text { com os problemas do ambiente de trabalho, no Colorado } \\
\text { nos EUA. }\end{array}$ & $\begin{array}{l}\text { Intensive Care } \\
\text { Med v. } 38 \\
\text { n.9 pp. } 1445- \\
1451\end{array}$ \\
\hline 24 & 2009 & $\begin{array}{l}\text { Leticia L. } \\
\text { Trindade; Liana } \\
\text { Lautert; Carmem } \\
\text { L.C. Beck }\end{array}$ & $\begin{array}{c}\text { Coping } \\
\text { mechanisms used } \\
\text { by non-burned out } \\
\text { and burned out } \\
\text { workers in the } \\
\text { Family health } \\
\text { strategy. }\end{array}$ & $\begin{array}{l}\text { Pesquisa quantitativa com } 86 \text { trabalhadores em } \\
\text { unidades da ESF, em Santa Maria, RS, Brasil: } 12 \\
\text { médicos, } 13 \text { enfermeiros, } 19 \text { técnicos de enfermagem, } \\
\text { cinco dentistas e oito auxiliares de consultório dentário, } \\
\text { num total de } 57 \text { profissionais, e } 29 \text { agentes comunitários } \\
\text { de saúde. Após responderem o questionário foram } \\
\text { divididos em } 2 \text { grupos com e sem burnout para } \\
\text { entrevistas. }\end{array}$ & $\begin{array}{c}\text { Revista } \\
\text { Latino- } \\
\text { Americana de } \\
\text { Enfermagem } \\
\text { v. } 17 \text { n.5 } \\
\text { pp. } 607-612\end{array}$ \\
\hline 25 & 2009 & $\begin{array}{l}\text { A.N.Nasrabadi; } \\
\text { H.Seif; M. Latifi; } \\
\text { N. Rassolzadeh; } \\
\text { A. Emami }\end{array}$ & $\begin{array}{l}\text { Night shift work } \\
\text { experiences } \\
\text { among Iranian } \\
\text { nurses: a } \\
\text { qualitative study. }\end{array}$ & $\begin{array}{l}\text { Estudo realizado com } 16 \text { trabalhadores de enfermaria, } \\
\text { com famílias de classe média, de quatro hospitais no Irã, } \\
\text { por meio de entrevistas estruturadas que focavam o } \\
\text { trabalho noturno. }\end{array}$ & $\begin{array}{l}\text { International } \\
\text { Nursing } \\
\text { Review v.56, } \\
\text { n-4 pp. } 498- \\
503\end{array}$ \\
\hline
\end{tabular}

FONTE: Informações extraídas dos artigos selecionados, analisados e organizados pela autora.

Nos artigos selecionados, considerando a AC, observaram-se três núcleos de sentido: 1) Dimensão sofrimento; 2) Dimensão estratégias de resistência e 3) Dimensão proposições para intervir na gestão do trabalho.

Quadro 2 - Núcleos de sentido, categoria e subcategorias da análise.

\begin{tabular}{|c|c|c|}
\hline NUCLEOS DE SENTIDO & CATEGORIA & SUBCAIEGORIAS \\
\hline \multirow[t]{3}{*}{ DIMENSAO SOFRIMENTO } & $\begin{array}{l}\text { Suscetibilidade dos } \\
\text { profissionais }\end{array}$ & Fisica / psiquica \\
\hline & Organização do trabalho & $\begin{array}{l}\text { Sobrecarga, conflitos, turnos de trabalho, } \\
\text { reconhecimento, salário e autonomia.. }\end{array}$ \\
\hline & Condições de trabalho & $\begin{array}{l}\text { Recursos materiais, espaço físico, equipamentos e } \\
\text { risco. }\end{array}$ \\
\hline DIMENSĀO ESTRATEGIAS & Enfrentamento & Individual / coletiva \\
\hline DE RESISTENCIA & Passividade & $\begin{array}{l}\text { Negação, resignação, desistência, silêncio, } \\
\text { assujeitamento e isolamento. }\end{array}$ \\
\hline DIMENSĀO PROPOSIÇŌES & gestão do trabalho & $\begin{array}{l}\text { Educação permanente, capacitação, qualidade de } \\
\text { vida no trabalho (QVT), políticas para resolução de } \\
\text { problemas, apoio psicológico... }\end{array}$ \\
\hline
\end{tabular}

FONTE: Neumann, 2014, p. 49 (Quadro adaptado). 


\section{Núcleo I - Dimensão Sofrimento}

Aparece sob a forma de queixas dos trabalhadores da saúde, exprimindo seus sentimentos, seus problemas físicos e/ou emocionais, críticas às condições e organização do trabalho. Isto contribui para investigar a pertinência de cada problema. Entende-se que as queixas dos trabalhadores podem abrir espaço de luta e resistência por melhores condições de trabalho, de acordo com Dejours (1990), como uma forma de expressar o sofrimento e a doença através da linguagem comum aos próprios trabalhadores. Nos artigos analisados os problemas relacionados ao trabalho foram expressos como impotência, sofrimento com a dor ou morte de pacientes, conflitos, irritabilidade, tristeza, desmotivação e depressão.

Do núcleo acima surgiram as seguintes categorias:

1. Suscetibilidade dos Trabalhadores: No que se refere a esta categoria, $48 \%$ dos textos representavam cansaço/fadiga/exaustão ; 36\% sofrimento com a dor ou morte de pacientes; $32 \%$ depressão ou burnout ; $28 \%$ sentimentos de impotência ; $24 \%$ dores físicas; $20 \%$ problemas com sono/insônia; $16 \%$ choro; $16 \%$ estresse; $16 \%$ dificuldade para separar questões de cunho pessoal do profissional; $12 \%$ sentimento de injustiça

2. Organização do Trabalho: Nesta categoria, $40 \%$ das queixas relacionava-se à sobrecarga, excesso de trabalho e demanda excessiva; $32 \%$ conflitos/dificuldade de relacionamento no trabalho; $28 \%$ falta de treinamento/capacitações técnicas; $20 \%$ falta de reconhecimento e valorização pessoal; $16 \%$ problemas com salário; $12 \%$ violência, agressões e assédio; $8 \%$ falta de autonomia.

3. Condições de Trabalho: Nesta categoria, $28 \%$ das queixas referiam-se à falta de recursos; $24 \%$ à precariedade do espaço físico e estrutura; $20 \%$ à falta de equipamentos e materiais; $12 \%$ ao risco de acidentes e exposição a outros riscos.

\section{Núcleo II - Dimensão Estratégias de resistências}

Para Dejours et al. (1994), os trabalhadores utilizam estratégias defensivas, que podem ser individuais ou coletivas, definidas pelo mecanismo pelo qual os trabalhadores buscam modificar, transformar e minimizar sua percepção da realidade que os faz sofrer. 
Sofrimento este que pode estar relacionado ao trabalho na atualidade, pois, o trabalho intenso ou sobrecarga são um dos maiores problemas da contemporaneidade capitalista.

Pode-se observar que os trabalhadores enfrentam os problemas no trabalho de várias maneiras, tais como: cerca de $28 \%$ referia-se a apoio nas relações interpessoais; $16 \%$ busca de ajuda profissional; $12 \%$ tentativa de diálogo e micro-negociações.

Por outro lado, na categoria passividade, observou-se que os trabalhadores podem torna-se passivos frente aos problemas do trabalho, ou seja, $20 \%$ buscam o silêncio, $16 \%$ a religiosidade; $12 \%$ se afastam do trabalho; $12 \%$ terapia/psicoterapia; $8 \%$ lazer e entretenimento; $8 \%$ atividade física; $8 \%$ e o restante o choro etc. Esta categoria pode ser representada pela negação, resignação, desistência, silêncio, isolamento e submissão, o que tem levado trabalhadores a adotarem estratégias de resistência de acordo com o nível de seus limites subjetivos (SATO, 1997).

Ademais, muitos trabalhadores buscam no enfrentamento uma forma de suportar o sofrimento no trabalho. Para Brant e Minayo-Gomez (2004) "Trabalhadores, gestores e profissionais da saúde constroem estratégias de resistência contra o adoecimento e instituem espaços de escuta para a manifestação do sofrimento" (BRANT \& MINAYOGOMES, 2008, p. 668).

Os autores mencionam ainda as resistências como sendo reativas e ativas, ou seja, na "resistência reativa, os trabalhadores reagem após a ocorrência de situações que podem desencadear processos de adoecimento" e na resistência como ação, ou ativa, "tudo ocorre de maneira bem diferente. O trabalhador age e crê em si mesmo espontaneamente, é capaz de manifestar o sofrimento, reconhecer e recusar dispositivos de adoecimento" (BRANT \& MINAYO-GOMEZ, 2009, p.245).

Moraes (2011) aponta ainda a negação e a racionalização como sendo mecanismos psicológicos mais frequentes nas estratégias defensivas. Para a autora, a “[...] negação pode ser sinalizada pela presença da desconfiança, de individualismo, de isolamento, e pela banalização das dificuldades da organização de trabalho", ou seja, os trabalhadores podem negar que de fato seu sofrimento é causado pelo seu ambiente de trabalho, enquanto a racionalização "se manifesta em falas que justificam as dificuldades do trabalho" (MORAES, 2011, p.103). 
Assim, não se pode negar que quem cuida da saúde também requer cuidados. No núcleo III serão listadas algumas proposições indicadas pelos trabalhadores visando a melhoria nas condições e organização do trabalho.

\section{Núcleo III - Proposições}

Este núcleo compreende a categoria gestão do trabalho, a qual foi a mais referida pelos trabalhadores nos artigos analisados.

As proposições apontadas por trabalhadores e autores apresentam importante relação com a prática da Educação Permanente em Saúde, para Ceccim (2005), é importante notar, que o conceito de Educação Permanente em Saúde está relacionado à gestão, formação e atenção em saúde.

A Educação Permanente em Saúde pode corresponder à Educação em Serviço, quando esta coloca a pertinência dos conteúdos, instrumentos e recursos para a formação técnica, submetidos a um projeto de mudanças institucionais ou de mudança da orientação política das ações prestadas em dado tempo e lugar. (Ceccim, p.162)

Partindo da premissa de que as organizações de saúde para funcionarem com qualidade dependem da formação, qualificação e uma boa gestão; a educação permanente é um grande desafio, pois confere ao trabalhador a possibilidade de atuar como protagonista efetivo do seu processo de trabalho o que envolve a necessidade de auto-interrogação de si mesmo (MERHY, 2005). Para o mesmo autor a educação permanente tem que ter a força de gerar no trabalhador as transformações de sua prática e de problematizar e construir novos pactos de convivência no âmbito individual e coletivo.

Com essa atitude, a reivindicação por espaços coletivos aparece tais como oficinas de trabalho, reuniões, programas de apoio psicológico que melhorem a qualidade de vida. No que tange à gestão do trabalho em saúde, as proposições colocadas giram em torno da capacitação dos gerentes para melhorar a organização do trabalho e saber lidar melhor com os conflitos. Tal proposição aparece de forma consistente nos depoimentos dos trabalhadores em saúde. As formas como lidam com o sofrimento e apontam para algumas sugestões que visam à melhoria dos processos de trabalho que afetam a vida e a saúde dos trabalhadores. 
Concordando com tais proposições, Lacaz (2000) enfatiza a importância da prática da qualidade de vida no trabalho e defende a conquista de um (re) planejamento do trabalho, com gestão participativa e com canais coletivos efetivos para negociações, já que a busca pela QVT envolve questões como salários, incentivos, participação nos lucros das empresas, autonomia, novas tecnologias e seu impacto para saúde e o meio ambiente.

\section{Conclusões}

Ao longo desse artigo buscou-se demonstrar que na área da saúde, apesar de todo investimento e potencial, existem várias limitações que têm sido objeto de críticas. E, quando se discute o mal-estar no trabalho na contemporaneidade, é cada vez mais importante partir da fala dos trabalhadores para pensar medidas de controle da nocividade do trabalho para a saúde.

Os trabalhadores mencionaram a importância das reuniões, dos espaços coletivos para discussão, da comunicação e políticas de gestão de conflitos, todavia, não é relatada uma mobilização nesse sentido, bem como existe ainda muita dificuldade para que se coloquem em prática os referidos espaços.

Nesta investigação, qualitativa e quantitativa, foi verificado que os trabalhadores constroem estratégias de resistência para amenizar o sofrimento, psíquico ou físico, pois não se pode negar que existe uma preocupação com os profissionais da área da saúde, tem buscado se reunir para debater e apontar as deficiências da gestão, por outro lado, não se pode negar também o direito dos trabalhadores a resistirem. Considera-se que identificar e analisar as estratégias de resistência, bem como as propostas para gestão do trabalho em saúde, podem fortalecer e apoiar as atuais políticas e práticas de atenção à saúde do trabalhador.

Entre os muitos desafios colocados, percebe-se que reconhecer a força e a abrangência das proposições dos trabalhadores da saúde pode reforçar a importância de investir-se em ações e políticas para melhorar a qualidade de vida no trabalho, criar espaços de discussão e dar voz ao trabalhador, individual e coletivamente. 


\section{Referências}

ANTUNES R.; DRUCK F. T. (Org.). Dimensões da precarização estrutural do trabalho. A perda da razão social do trabalho: terceirização e precarização. São Paulo: Boitempo, 2007. p. 13-22.

BARDIN L. Análise de conteúdo. $3^{\mathrm{a}}$ ed. Lisboa: Edições 70, 2004.

BLANCH J.M. et al. El capitalismo organizacional como factor de riesgo psicosocial: efectos psicológicos colaterales de las nuevas condiciones de trabajo dictadas por el capitalismo académico y sanitário implantado en universidades y hospitales no lucrativos de la red pública. Proyeto de pesquisa, Barcelona: Universidade Autonoma de Barcelona, 2007.

BRANT L. C.; MINAYO-GOMEZ C. Manifestação do sofrimento e resistência ao adoecimento na gestão do trabalho. Saúde e Sociedade, v. 18, n. 2, p. 237-247, 2009.

BRASIL. Presidência da República. Lei 8080. Diário Oficial da União, Brasília, DF, 19 set. 1990.

Ministério da Justiça. Programa

Nacional de Direitos Humanos. PNDH II. Brasília, 2002.

BRUCH V. L. A.; MONTEIRO J. K. Relações entre colegas como manifestações de resistência ao adoecimento no trabalho. In: FERREIRA M. C. et al. (Org.). Dominação e resistência no contexto trabalho-saúde. São Paulo: Mackenzie, 2011.
CECCIM R. B. Educação permanente em saúde: desafio ambicioso e necessário. Interface Comunicação Saúde Educação, Botucatu, v. 9, n. 16, p. 162-168, set. 2004/fev. 2005.

CODO W. Um diagnóstico integrado do trabalho com ênfase em saúde mental. In: JACQUES M.G.; CODO W. (Org.). Saúde mental \& trabalho: leituras. Petrópolis, Vozes; 2002. p. 173-90.

DEJOURS C. A. loucura do trabalho: estudo de psicopatologia do trabalho. São Paulo: Cortez, 1987.

DEJOURS C.; ABDOUCHELI E.; JAYET C. Psicodinâmica do trabalho: contribuições da Escola Dejouriana à análise da relação prazer, sofrimento e trabalho. São Paulo: Atlas, 1994.

FERREIRA A. B. H. Novo dicionário Aurélio século XXI. $3^{\mathrm{a}}$ ed. Rio de Janeiro: Nova Fronteira; 1999.

FOUCAULT M. Microfísica do poder. $6^{\mathrm{a}}$ ed. Rio de Janeiro: Graal, 1986.

LACAZ F. A. C. Qualidade de vida no trabalho e saúde/doença. Ciência e Saúde Coletiva, São Paulo, v. 5, n. 1, p. 151-161, 2000 .

LACAZ F. A. C, et al. Gestão do trabalho em saúde em dois sistemas municipais do Estado de São Paulo: implicações operacionais e psicossociais para uma política de pessoal. Relatório técnico. São Paulo, 2014. 
LAROUSSE C. Grande dicionário Larousse cultural da Língua Portuguesa. São Paulo: Editora Nova Cultural, 1999.

LAURELL A. C.; NORIEGA M. Processo de produção e saúde: trabalho e desgaste operário. São Paulo: Hucitec, 1989.

MENDES A. M. (Org.). Violência no trabalho: perspectivas da psicodinâmica, da ergonomia e da sociologia clínica. São Paulo: Distribuidora Editora Cultura Cristã, 2010.

MENDES R.; DIAS E. Da medicina do trabalho à saúde do trabalhador. Revista de Saúde Pública, São Paulo, v.25, n. 5, p. 341-349, 1991.

MERHY, E. E. O desafio que a educação permanente tem em si: a pedagogia da implicação. Interface Comunicação Saúde Educação, Botucatu, v. 9, n. 16, p. 172174, 2005.

MERLO A. R. Psicodinâmica do trabalho. In: JACQUES M. G.; CODO W. (Org.). Saúde mental \& trabalho: leituras. Petrópolis: Vozes, 2002. p.130142.

MORAES, R. D. As estratégias de defesa e o enfrentamento do sofrimento no trabalho com automação no polo industrial de Manaus. In: FERREIRA, M. C. et al. (Org.). Dominação e resistência no contexto trabalho-saúde. São Paulo: Mackenzie, 2011.

NEUMANN A. P. F. M. As estratégias de resistência ao sofrimento psíquico e físico relacionadas à gestão do trabalho em saúde: um estudo de revisão sistemática da literatura. 2014. [Dissertação de
Mestrado em Saúde Coletiva]Universidade Federal de São Paulo, São Paulo, 2014.

OIT - Organización Internacional del Trabajo. OMS - Organización Mundial de la Salud. Diretrices marco para afrontar la violencia laboral en el sector de la salud. Ginebra, 2002.

OLIVEIRA, S. G. Proteção Jurídica à saúde do Trabalhador. São Paulo: Editora LTR Ltda, 2002.

OMS - Organización Mundial de la Salud. Informe mundial sobre la violencia y la salud. Washington, D.C.: OPS Organización Panamericana de la Salud; 2002.

SANTOS, L. F. A. Apostila de Metodologica da pesquisa científica II. Itapeva: Faculdade Metodista de Itapeva, 2006.

SATO, L. Astúcia e ambigüidade: as condições simbólicas para o replanejamento negociado do trabalho no chão de fábrica. [Tese de Doutorado], Instituto de Psicologia, Universidade de São Paulo, São Paulo, 1997.

SELIGMANN-SILVA E. Desgaste mental no trabalho dominado. Rio de Janeiro: Editora UFRJ, 1994.

VIANA M. T. Direito à resistência: possibilidades de autodefesa do empregado em face do empregador. São Paulo: Editora Ltda, 1996. 